\title{
TECHNOLOGY AND RESILIENCE IN THE RECONSTRUCTION PROCESS. A CASE STUDY
}

\author{
M. Rotilio* \\ Dept. of Civil, Architecture, Environmental Engineering, University of L’Aquila, 67100 L'Aquila, Italy - \\ marianna.rotilio@univaq.it
}

Commission IV

KEY WORDS: Smart tunnel, Resilience, Underground services, Technology, District Information Modeling, L’Aquila

\begin{abstract}
:
In every field concerning post-disaster reconstruction, not only in engineering, technology plays a leading role and, just as resilience, it has become the goal that every action should achieve. In light of what has been claimed, this paper intends to critically illustrate one of the most interesting elements of technological innovation underway in the city of L'Aquila hit by the 2009 earthquake. The reference is the so-called "smart tunnel", a system of functional and management rationalization of the underground services of the city. The work was divided into two portions called "Excerpts" where the first one is currently 93\% completed and highlighted the presence of intrinsic criticalities in the work and in the context. In order to avoid irrational and random conditions that could inevitably lead to a safety lack, related to the excerpts II a methodology is being developed, based on District Information Modeling. It is configured as a control and management tool for the whole system which will allow the interference management inspired by principles of rationality and safety. The smart tunnel system is part of a series of other public and private initiatives, aimed at a widespread experimentation of advanced technologies that deals with the renewal of infrastructures, services and mobility, telecommunications. These innovations mainly concern the L'Aquila historical centre but also the outskirts and follow the principles of the smart city and related to the resilience development.
\end{abstract}

\section{INTRODUCTION}

After the occurrence of a natural disaster, the actions that follow may be framed in two main "fields", that are those concerning the immediate post-disaster and those aimed at ensuring longterm reconstruction (Vona et al., 2018). The first include all the activities that have the purpose to secure the population as well as the territory involved. The other field includes the actions that intend to give back a safe and reconstructed place to its community. While most of the action plans have been defined to allow return to functionality in a short time (Zhang et al., 2017; Bocchini and Frangopol, 2010), the long-term reconstruction has received less attention (Wang et al., 2020). In this context, during the last years there has been a transition from the concept of the "as it was, where it was" reconstruction to the "building back better" one, giving considerable importance to the issue of resilience as risk mitigation element (Cutter et al., 2008; Cimellaro et al., 2010; Vona et al., 2018) and to the role played by technology. In this matter, many topics are being object of research. For instance, Yang et al. (2015) highlight the importance to use monitoring systems of the mountain ranges affected by the earthquake to control the land instability, that threatens the building reconstruction. Van Leersum and Arora (2011) illustrated how the correct selection of technological solutions contributed to mitigate the seismic risk. Dominici et al. (2017) believe that UAV photogrammetry is an excellent survey strategy in dangerous conditions to humans, while Alicandro and Rotilio (2019) used UAV photogrammetry for resilience management in the reconstruction plans of historical urban centres. Lucarelli et al. (2018) highlight the support provided by BIM and digitization systems in the reconstruction context, in particular with regard to the construction site and the execution phase. Instead, Brusaporci et al. (2017) investigated the augmented reality role as a complex storytelling tool, a narration between history and reality. Potenza et al. (2015) inquired the structural monitoring efficiency of a monumental building through the use of lowcost wireless sensor network. In every field concerning post-disaster reconstruction, not only in engineering, technology plays a leading role and, just as resilience, it has become the goal that every action should achieve. In light of what has been claimed, this paper intends to critically illustrate one of the most interesting elements of technological innovation underway in the city of L'Aquila, sharply hit by the 2009 earthquake. The reference is the so-called "smart tunnel", a system of functional and management rationalization of the underground services of the city. It is probably the largest public work in the postearthquake reconstruction process. In fact, the latter surely has had a strong impact on the rebuilding course. This system is part of a series of other public and private initiatives, aimed at a widespread experimentation of advanced technologies that deals with the renewal of infrastructures, services and mobility, telecommunications. These innovations mainly concern the L'Aquila historical centre but also the outskirts and follow the principles of the smart city and related to the resilience development (Brusaporci et al. 2018; Di Ludovico and Dominici, 2019).

\footnotetext{
* Corresponding author
} 


\section{THE SMART TUNNEL}

\subsection{General framework - Excerpt I}

After the April 2009 earthquake, the so-called "red zone" was established in the L'Aquila historical centre and the unavailability of all the public and private buildings existing in the municipal area was ordered (Ordinance no. 67 of 08.04.2009). Therefore, the historical city centre, one of the largest (about 160 ha) and noteworthy in Italy (Di Ludovico, 2019), found itself to be emptied of its inhabitants and visitors, leaving room for technicians and companies responsible for the safety works execution. It was in that historical moment that the network of underground services of the city was completely redesigned and it happened with an entire urban center "available" (Fig. 1). The smart tunnel was in fact scheduled by the Commissioner for Reconstruction Decree n. 24 of 24.10.2010 and subsequent CIPE Resolution n. 43 of 2012, when the intensive reconstruction of the historical centre had not yet begun. It takes the form of an underground tunnel, that is walkable by technicians, where the main city services are housed, as sewage (black and white water), electricity, telecommunications and remote control. The connections to the services by the individual users are also included inside it (Fig. 2-3). It is clear that only in a context of "heavy" reconstruction could be possible to conceive such an ambitious project. Among the main advantages there is the efficiency of the rainwater collection system, the networks rationalization, the possibility to implement the existing infrastructures with other network services, the fight against the frequent occurrence of illegal connections and, clearly, the easy way to identify and solve faults. This last operation may be carried out without excavating or interrupting urban traffic.

Overall, the smart tunnel will be able to optimize and improve the management of the underground services of the city.
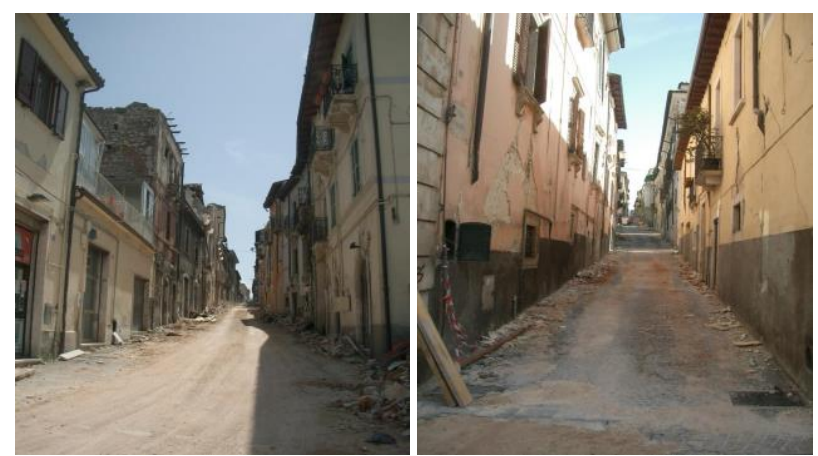

Figure 1. On the left Via Roma, on the right Via Cascina (2009)

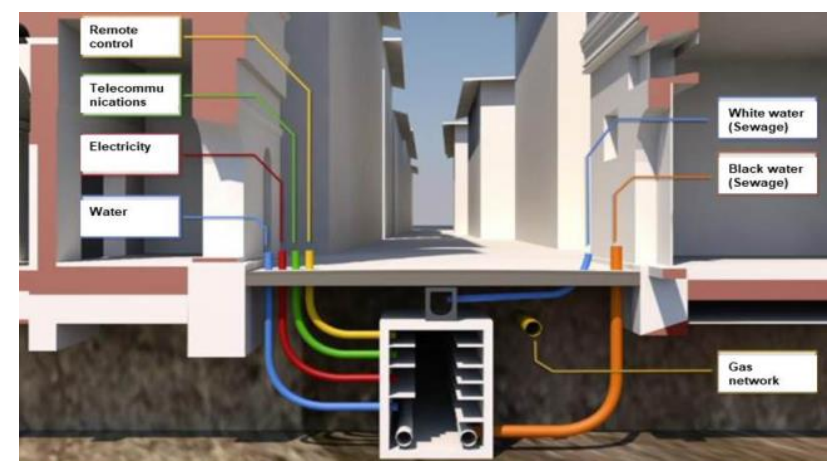

Figure 2. Analysis section of the underground tunnel with the identification of all the housed services

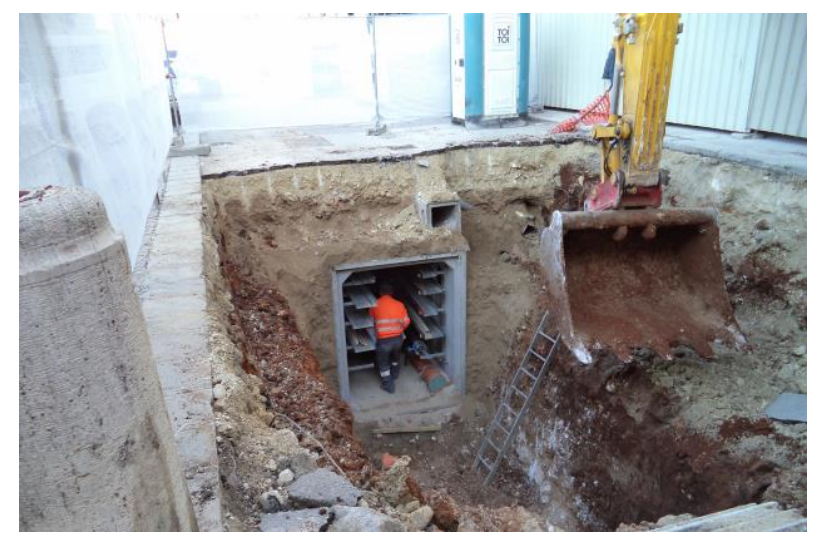

Figure 3. View of the internal part of underground tunnel set up along Corso Vittorio Emanuele II

On the other hand, with regard to this complex infrastructure management, a specific study was conducted that makes use of BIM technology (Brusaporci et al., 2018).

The work was divided into two portions called "Excerpts" (Fig. 4).

The first excerpt concerns the so-called "Central axis" which affects the historical city centre and which is currently $93 \%$ completed (https://www.pumslaquila.it/). It provides for the construction of an underground tunnel $12,500 \mathrm{~m}$ long, for a number of users served equal to 2,354 (Table 1).

The second excerpt could be defined as a sort of ring around the central axis system, that connects the latter to the immediate city outskirts.

Owing to its considerable extension, it was in turn divided into five lots. In particular, lot I concerns the San Pietro district, the II is related to the San Marciano district and the III is the Villa Comunale district. These three neighborhoods were built in the twentieth century and act as a "crown" of the historical centre of L'Aquila, a city whose foundation dates back to the first half of the thirteenth century.

Going on, lots IV and V are represented by two important urban streets, Via Strinella and Via della Croce Rossa respectively, which cross populous urban districts.

In the second excerpt, the works of lot II, San Marciano, have been started, while the administrative-preliminary procedure is being completed for the other four.

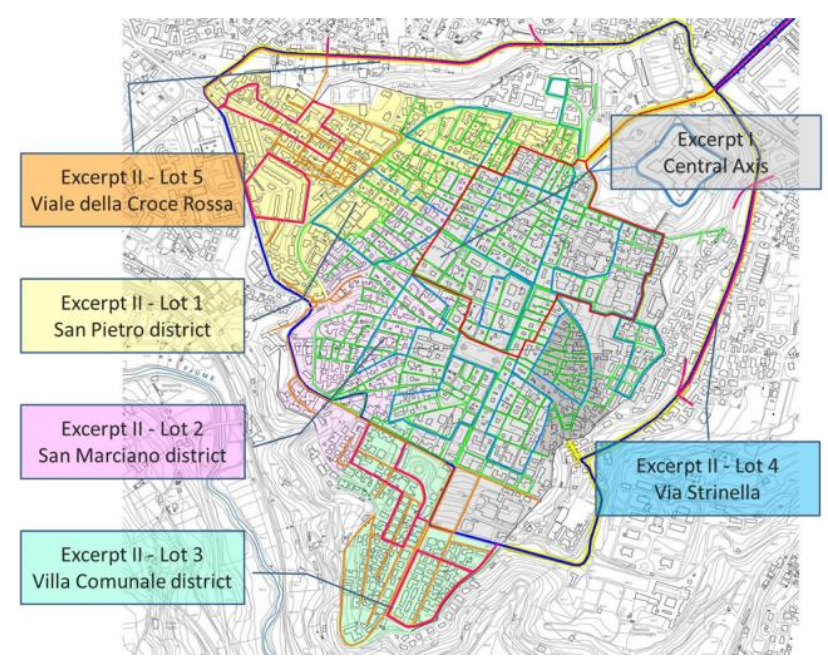

Figure 4. The first excerpt or "Central axis" is in gray; the five lots that represent the second part are identified with the colors 


\begin{tabular}{|l|c|c|}
\hline Reference elements & \multicolumn{2}{|c|}{ Quantity } \\
\hline Number of served & \multicolumn{2}{|c|}{2.354} \\
utilities & \multicolumn{2}{|c|}{} \\
Black sewer lenght & 31,225 & $\mathrm{~m}$ \\
White sewer lenght & 17,514 & $\mathrm{~m}$ \\
Waterworks lenght & 52,215 & $\mathrm{~m}$ \\
Tunnel lenght & 12,500 & $\mathrm{~m}$ \\
Involved road area & 103,550 & $\mathrm{~m}^{2}$ \\
Excavation volume & 77,150 & $\mathrm{~m}^{3}$ \\
Auction based amount & $32,998,878.61$ & $€$ \\
Contractual amount & $27,823,566.66$ & $€$ \\
\hline
\end{tabular}

Table 1. Work data (Excerpt 1 - Central Axis)

\subsection{Critical issues and interferences - Excerpt I}

A so complex and important technological system as the smart tunnel under construction in L'Aquila, obviously determines the occurrence of critical conditions: some of them are intrinsic to the system, while others are determined by external factors. Among the ones that are intrinsic to the system it is possible to include (Rotilio and Di Bacco, 2020):

1. The need to gather and organize all existing networks in a single path, and consequently, the requirement to modify the layout of some of them. This condition implies the collaboration of all managers;

2. The services continuity guarantee to users during the work construction, by providing temporary network bypasses in the sections affected by the passage of the tunnel (Fig. 5);

3. The interference management with the gas network which, since it will not be housed in the smart tunnel, will not have to be dismantled. Moreover, this network has undergone a recent renewal. Therefore, it has to be effectively safeguarded;

4. The connection management of the new sewerage system with the existing one because the former is a parted model, while the existing one is unitary.

The critical issues listed above were known from the stage of the contract conception. For this reason, they have been the subject of careful planning, in such a way as to solve them before the execution, in order to avoid delays and variations during the work.

Among the major drawbacks that were caused by the context, there is the significant impact that the reopening of some commercial premises had on the construction of the infrastructure, as well as the return to the historical centre of a limited number of citizens, in addition to numerous tourists. In fact, this work, although conceived at a time when the city was empty, was begun in 2016, when L'Aquila was in the reconstruction phase. Therefore, this situation has to be taken into account when site layouts are defined, mainly in relation to the creation of "safe" accesses and paths.

Another criticality determined by the context that had a remarkable effect, was that related to archaeological finds (Fig. 6) of different value and entity which, in a medieval city like L'Aquila, it is easy to discover.

In some cases, it was sufficient to temporarily suspend the works to detect and geo-reference the finds. Instead, in other situations, it was necessary to modify the infrastructure project by drafting a variant during construction. This situation occurred whenever the importance and value of the finds did not allow for compromises with the innovative tunnel.
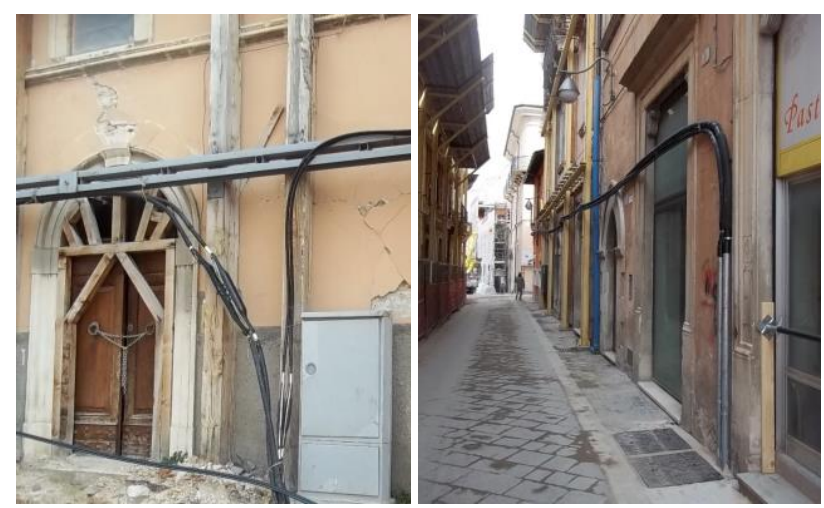

Figure 5. On the left, the temporary by-pass related to the data network (prepared by Telecom and Fastweb); on the right, the one related to the water network

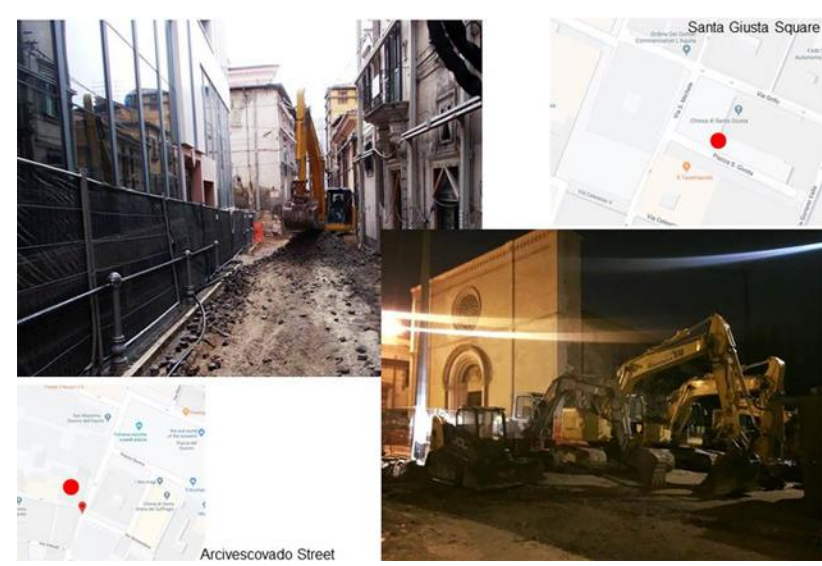

Figure 6. Among the streets where archaeological finds were discovered there are also via dell'Arcivescovado and Piazza

\section{Santa Giusta}

Thus, it could be understood how the construction of the underground service network took place under constant surveillance by the Archeology Superintendency. In addition to this, the work also saw the involvement of other entities, primarily the Municipality of L'Aquila, especially with regard to the issue of mobility and construction sites.

As aforementioned, in fact, the smart tunnel was designed within a historical urban context, characterized by small spaces, limited to allow the passage of vehicles or the materials storage (De Berardinis et al., 2018). This condition represents an intrinsic system crticical issue, to which, be that as it may, others linked to the simultaneous presence of many reconstruction sites have been added.

The construction site project envisaged the subdivision of excerpt I into seven areas with a base camp located outside of them. For each of these areas the detailed project was developed with:

1. The identification of the process phases with the related durations;

2. The planning of the excavation fronts;

3. The definition of the work schedule;

4. The preparation of site layouts, within which the auxiliary factors were specified, i.e. service areas and equipment. 
This approach would have made it possible to realize different lines of the new infrastructure simoultauneously, completing it over a period of twenty-four months. Nevertheless, this forecast was developed considering the smart tunnel construction regardless of the city reconstruction. Instead, the area affected by the works was characterized by the presence of many open construction sites. In fact, according to data provided by the Reconstruction Coordination Office, Private Reconstruction Sector, in March 2016, in the urban area affected by the construction of excerpt I, 147 authorizations for construction site were requested (Fig. 7).

This situation has continued over time, causing continuous and sudden changes in the scenario regarding the occupied public land, the available roads, the active construction sites. It also inevitably forced the actors involved in the smart tunnel construction site, and in those which interfere with it, to draft numerous and increasingly detailed construction site variants.

The effect of this uncontrolled contemporaneity of different processes, objectives and actors has resulted in the absolute rationality lack in the executive process, as well as problems related to the compliance with contractual deadlines, planning and safety.

Clearly, the same kind of problems also occurred in the reconstruction sites, strongly impacted by the execution of the innovative infrastructure (Fig. 8).

In 2018 it was necessary to design an ongoing variant of the smart tunnel project. On that occasion, an attempt was made to redesign the construction site according to principles inspired by rationality and safety, but also in this case the continuous changes of scenario and surrounding conditions determined the failure of the planning.

\subsection{Considerations and methodological approach for the Excerpt II realization}

The experience of the construction site of the new L'Aquila underground services network, excerpt I, highlighted the presence of intrinsic criticalities in the work and in the context, that were illustrated in the previous paragraph. The latter may be summarized below:

1. Critical issues inherent in the work execution in a historical urban centre (quality and size of the available spaces; difficulties that involve: storage, displacement of people, materials and vehicles, presence of adjacent buildings, presence of scaffolding or elements linked to safety and to the service);

2. Presence of finds.

The impact of these elements was managed and mitigated in order to develop the executive process according to the principles of rationality and safety.

Anyway, the critical issue with the greatest impact was identified in the simultaneous presence of the reconstruction sites, as well as users and commercial activities. This condition denounces the absolute lack of higher-order programming that could allow:

1. Process planning;

2. Interventions coordination;

3. Predisposition design of the organizational supports (services, equipment, infrastructures);

4. Regulation of interconnections and interference;

5. Management of emergencies and first aid;

6. Safety requirements definition.

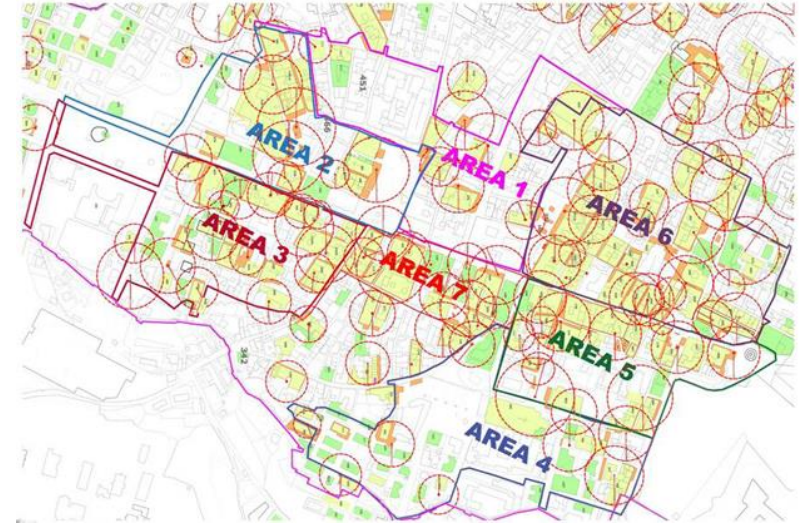

Figure 7. The image shows the division into seven areas of the urban built heritage affected by the works in Excerpt I. Within each of them, the dotted circles that represent the arm of the installed cranes are identified, while the yellow color indicates

the reconstruction sites that were active in March 2016

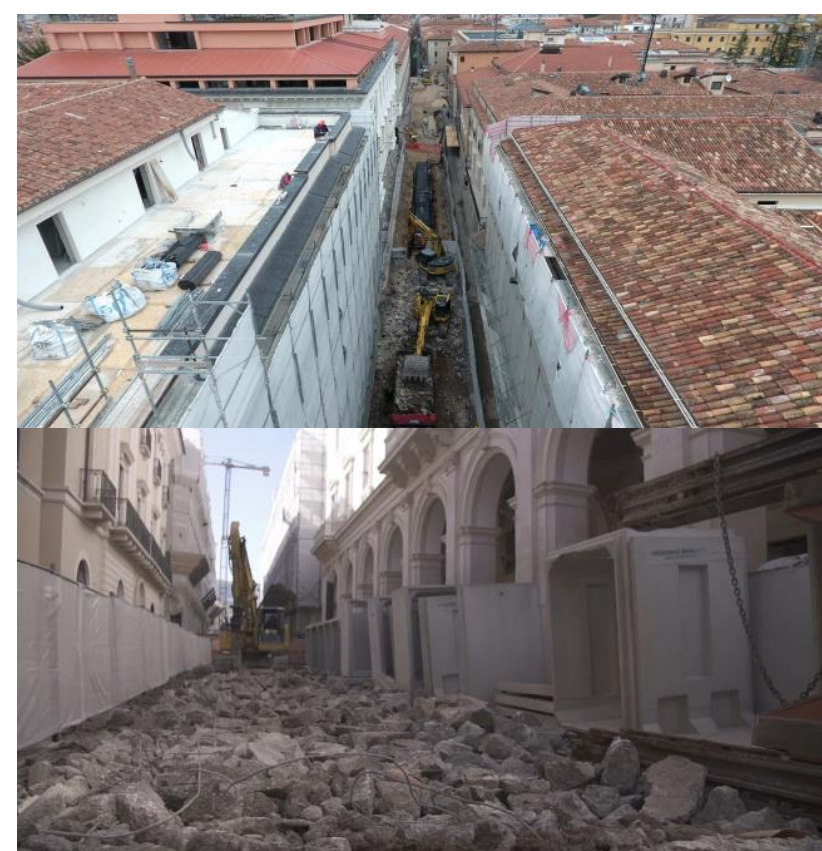

Figure 8. Photos of Corso Vittorio Emanuele, one of the main access roads to the L'Aquila historical centre, that is forbidden to the means of post-earthquake reconstruction to allow the construction of the smart tunnel. The reconstruction vehicles were forced to use smaller secondary roads

There is a reference to a programmatic tool that should have defined the actions and strategies through which it was possible to regulate and manage in its entirety the so-called "largest construction site in Europe".

This lack is even more serious in this period, when the construction phase of excerpt II is starting. It has shown additional criticalities with respect to the central axis. As mentioned, in fact, excerpt II is divided into five different lots and every execution has been entrusted to as many companies which have different organizational management methods. To date, for example, the executive project of lots 1 and 2 has been validated. 
The first is about a construction site project according to a subdivision into seven different macro-areas, each equipped with logistical-assistance services (first aid shacks, changing rooms, offices and toilets), boxes for equipment storage, washing stations for vehicle and wheels. In addition, each area is expected to be closed with a construction site fence and equipped with an independent accessibility and road system. On the other hand, the project for the lot 2 construction provides for a single basic logistics area, that could be useful to accommodate the service structures such as offices, changing rooms, canteens and toilets, as well as the temporary storage of the necessary materials and artifacts. From an operational point of view, the project foresees that the interventions are carried out according to a chronological order and according to three simultaneous excavation fronts.

Simply by analyzing the first two projects, completely different methods and management systems are found. This reality will probably also occur in the other three lots of Extract II. Likewise, it could be possible to expect a complexification of the general organization following the possible concurrent development of the different construction sites of the five lots.

For the time being, a further critical element is driven by the fact that the urban fabric affected by excerpt II has largely been returned to the city and its citizens. So, a detailed analysis of the traffic and mobility plan will have to be performed.

In the meantime, a continuous comparison and information exchange with the competent municipal office will be necessary.

Finally, an additional element to be noted concerns the overlap between the smart tunnel construction site and that of the strategic urban projects, such as PUMS, Urban plans for sustainable mobility (https://www.pumslaquila.it/), project of Via Roma and Porta Barete, Biciplan, Urban Greenway, in addition to the numerous further initiatives implemented with the aim of making L'Aquila a theater of technological experimentation.

In light of what has been argued, it is clear that the construction site of excerpt II needs to be perfectly planned and managed, in order to avoid irrational and random conditions that could inevitably lead to a safety lack. For this purpose, a methodology is being developed aimed at identifying a higher order tool based on coordination between the institutions and actors involved. This methodology is based on District Information Modeling, named DIM, that is a BIM implementation on an urban scale. It allows to use traditional techniques with advanced technologies, integrating in a suitable way geometric and alphanumeric data, thanks to the interoperability between two different domains, BIM and GIS. Although officially recognized methodologies do not exist today, "it is evident that the importation and the aggregation in GIS of the geometries and all the data necessary to accurately represent the built heritage, guarantees that the efficiency and power of BIM may be exploited, extended and connected in geographic space at different scales" (Osello, 2015). In fact, this methodology involves the extrapolation of a model from the GIS, that is able to communicate with the BIM domain. Within the latter, the entire territory under examination is created, with associated parametric information. These characteristic and characterizing attributes are divided into LOG (geometric information attributes) and LOI (non-geometric information attributes) and they have made it possible to collect measurable and nonmeasurable information.

The relevant information mainly concerns the contents of the webgis platform of the Municipality of L'Aquila (http://webgis.comuneaq.usra.it/mappa_def.php), which allows to view the reconstruction progress of all the municipality locations with the related active or completed construction sites; at the same time, it involves the traffic and urban mobility plan, the sensitive receptors analysis (schools, hospitals, nursing / retirement homes), the executive project of the underground utilities network of the city. On the basis of the continuous updates of the integrated parametric model created, it will be possible to manage better the construction site of excerpt II to rationally solve any interference with the urban system.

It is obvious that the integrated parametric model may be continuously implemented, both in terms of content and definition level, and used by the institutions involved in the city reconstruction and planning as well as the smart tunnel contract management. It is configured as a control and management tool for the whole system which, flexible and subject to continuous updating, will allow the interference management inspired by principles of rationality and safety (Fig. 9).

\section{CONCLUSIONS}

In the context of the reconstruction of the city of L'Aquila after the 2009 earthquake, many activities are carried out in order to achieve systemic resilience. And this purpose is also sought through the use of technology that plays a priority role in every area, not just in engineering one. In this regard, this paper illustrates a technological innovation element under construction in the heart of the city of L'Aquila, that is the socalled "smart tunnel". It is a system of functional and managerial rationalization of the underground services of the city and, probably, it represents the largest public work in the post-earthquake reconstruction process, which has had a strong impact on it. In fact, the lack of a programmatic tool that should have defined the actions and strategies through which it was possible to regulate and manage in its entirety the so-called "largest construction site in Europe", has frequently highlighted the deficiency of rationality and safety in the rebuilding process. Therefore, in connection with the construction of the second excerpt of the smart tunnel, a methodology is being developed that will allow coordination between the institutions, the project forecasts and the actors involved. This approach is based on the use of the District Information Modeling, DIM, that is a BIM implementation on an urban scale. As a consequence, the resulting integrated parametric model may be continuously implemented and made available to the institutions involved. It would be elastic and subject to continuous updating, allowing an interference management based on principles of rationality and safety.

\section{ACKNOWLEDGEMENTS}

The topics illustrated in this paper are part of the research developed by the author into the study named "Solutions for hydraulic criticalities in the implementation of the subservice system of the Municipality of L'Aquila". In this matter, Eng. Ph.D. Anna Rita Scorzini is the scientific director of the research. This research is funded by Gran Sasso Acqua S.p.A., L'Aquila, Italy.

Images 1 to 8 and Table 1 were created by the author on the basis of the documentation provided by $(C$ Assecentrale, for the first excerpt, () Gran Sasso Acqua S.p.a., for the second excerpt. Image 9 was elaborated by the author (C) MariannaRotilio. 


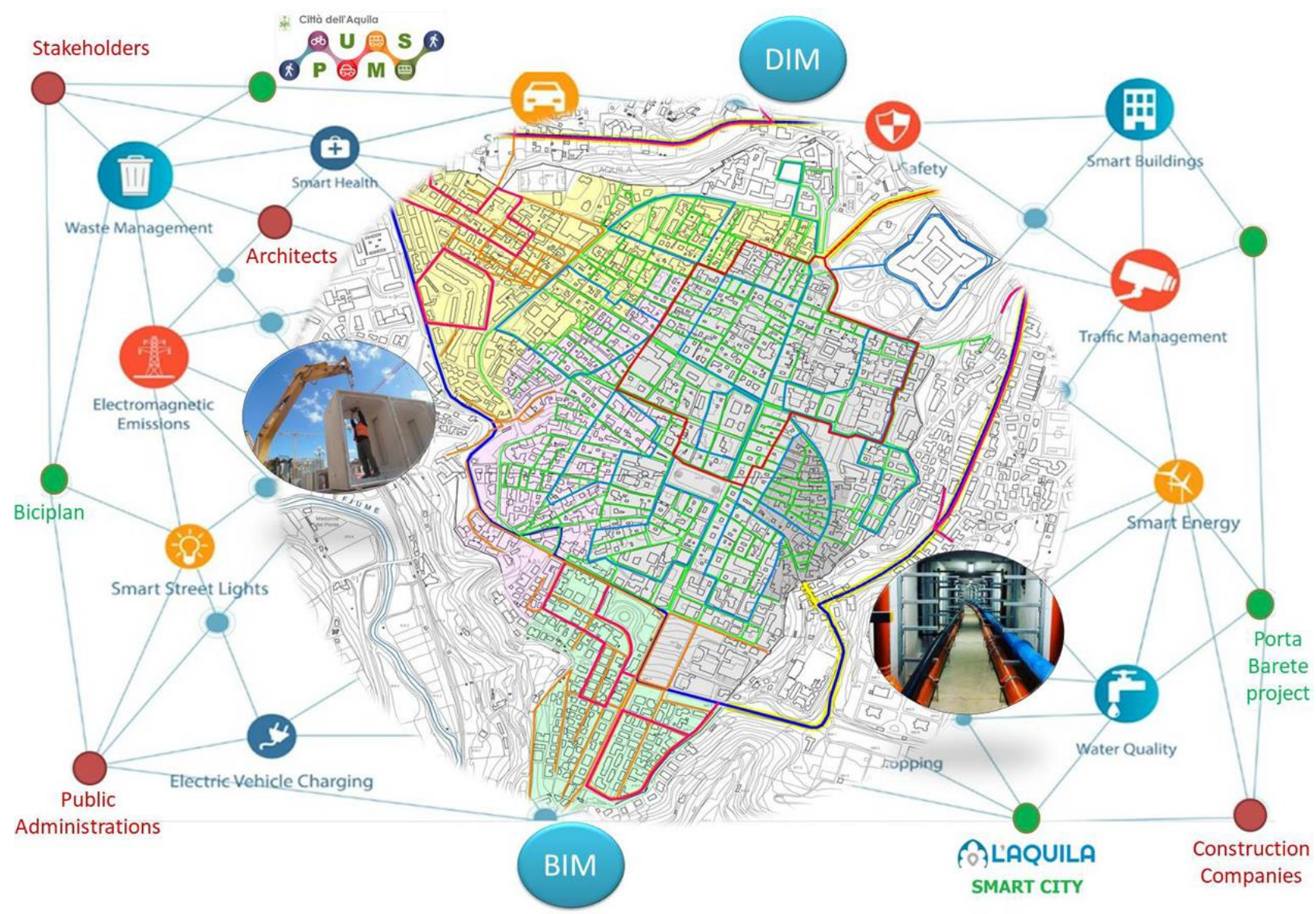

Figure 9. Scheme of the developed programmatic tool. It is based on District Information Modeling, DIM, that is a BIM implementation on an urban scale

\section{REFERENCES}

Alicandro, M., Rotilio, M., 2019. Uav photogrammetry for resilience management in reconstruction plan of urban historical centres after seismic events. A case study, Int. Arch. Photogramm. Remote Sens. Spatial Inf. Sci., XLII-2/W11, 5561, https://doi.org/10.5194/isprs-archives-XLII-2-W11-55-2019

Bocchini, P., Frangopol, D.M., 2012. Optimal Resilience- and Cost-Based Postdisaster Intervention Prioritization for Bridges along a Highway Segment, Journal of Bridge Engineering, 17(1), https://doi.org/10.1061/(ASCE)BE.1943-5592.0000201

Brusaporci, S., Ruggieri, G., Sicuranza, F., Maiezza, P., 2017, Augmented Reality for Historical Storytelling. The INCIPICT Project for the Reconstruction of Tangible and Intangible Image of L'Aquila Historical Centre. Proceedings 1, 1083, https://doi.org/10.3390/proceedings1091083

Brusaporci, S., Maiezza, P., Tata, A. 2018. Building information modelling per la gestione e manutenzione di "L'aquila - Smart tunnel", DN Building Information Modeling, Data \& Semantics, 2, 27-35

Cimellaro, G.P., Reinhorn, A.M., Bruneau, M., 2010. Framework for analytical quantification of disaster resilience. Engineering Structures, 32(11), 3639-3649, https://doi.org/10.1016/j.engstruct.2010.08.008.
Cutter, S.L., Barnes, L., Berry, M., Burton, C., Evans, E., Tate, E., Webb, J., 2008. A place-based model for understanding community resilience to natural disasters. Global Environmental Change. 18(4), 598-606, https://doi.org/10.1016/j.gloenvcha.2008.07.013.

De Berardinis, P., Di Giovanni, G., Laurini, E., Rotilio, M., 2018. Progettare l'organizzazione del cantiere di recupero nell'ambito della ricostruzione post sismica a L'Aquila, In Minutoli F. (Ed) L'intreccio dei saperi per rispettare il passato interpretare il presente salvaguardare il futuro, VI Edizione Convegno ReUso, Gangemi Editore, ISBN13: 9788849236590 ISBN10: 9788849236590

Di Ludovico, D., 2019. Resilienza urbana e città in ricostruzione: la funzione delle tecnologie, Recupero e conservazione n. 155 , pag. 49-52, ISSN 2283-7558

Di Ludovico, D., Dominici, D., 2019. How to combine the Smart City and the historic centre: suggestions from a case study. In Bologna S. (Ed.) A set of Good Practices and Recommendations for Smart City Resilience Engineering and Evaluation, AIIC Editor, ISBN 9788893495974

Dominici, D., Alicandro, M., Rosciano, E., \& Massimi, V., 2017. Multiscale documentation and monitoring of L'Aquila historical centre using UAV photogrammetry. International Archives of the Photogrammetry, Remote Sensing \& Spatial Information Sciences, 42. 
The International Archives of the Photogrammetry, Remote Sensing and Spatial Information Sciences, Volume XLIV-3/W1-2020, 2020 Gi4DM 2020 - 13th Geolnformation for Disaster Management conference, 30 November-4 December 2020, Sydney, Australia (online)

Smart tunnel Asse Centrale, https://sottoserviziaq.it/ (access on: 18.08.2020)

Piano Urbano Mobilità Sostenibile, https://www.pumslaquila.it/ (access on: 24.08.2020)

Piattaforma di gestione e monitoraggio della ricostruzione, http://webgis.comuneaq.usra.it/mappa_def.php (access on: 24.08.2020)

Yang, W. T., Wang, M., Kerle, N., van Westen, C. J., Liu, Y., \& Shi, P. J., 2015. Analysis of changes in post-seismic landslide distribution and its effect on building reconstruction. Natural hazards and earth system sciences, 15, 817825. https://doi.org/10.5194/nhess-15-817-2015

Lucarelli, M., Laurini, E., Rotilio, M., De Berardinis, P. 2018. Metodo BIM: gestione dei cantieri edilizi nei centri colpiti da calamità naturali, In Minutoli F. (Ed) L'intreccio dei saperi per rispettare il passato interpretare il presente salvaguardare il futuro, VI Edizione Convegno ReUso, Gangemi Editore, ISBN13: 9788849236590 ISBN10: 9788849236590

Ordinanza sindacale n. 67 del 08.04.2009, Sisma 06.04.2009 Misure urgenti al fine di fronteggiare l'emergenza: ordinanza di inagibilità.

Osello, A., 2015. Introduzione. In Osello A. (Ed.) Building information modelling geographic information system augmented reality per il facility management, Palermo, Dario Flaccovio Editore, ISBN 9788857904788

Potenza, F., Federici, F., Lepidi, M.m Gattulli, V., 2015. Longterm structural monitoring of the damaged Basilica S. Maria di Collemaggio through a lowcost wireless sensor network, Journal of Civil Structural Health Monitoring, 5(5), 655-676, https://doi.org/10.1007/s13349-015-0146-3.

Rotilio, M., Di Bacco, M., 2020. Lo smart tunnel. L'innovazione nella ricostruzione, Recupero e conservazione $\mathrm{n}$. 157, 2020, pag. 35-37, ISSN 2283-7558

Vona, M., Mastroberti, M., Mitidieri, L., Tataranna, S., 2018. New resilience model of communities based on numerical evaluation and observed post seismic reconstruction process. International Journal of Disaster Risk Reduction, 28, 602-609, https://doi.org/10.1016/j.ijdrr.2018.01.010.

van Leersum A., Arora, S., 2011. Implementing seismicresistant technologies in post-earthquake Pakistan: A process analysis of owner driven reconstruction, Habitat International, $35(2)$, 254-264, https://doi.org/10.1016/j.habitatint.2010.09.009.

Wang, Y., Wang, N., Lin, P., Ellingwood, B., Mahmoud, H., 2020. Life-cycle analysis (LCA) to restore community building portfolios by building back better II: Decision formulation, $\begin{array}{lll}\text { Structural Safety, } & 84, & 101921,\end{array}$ https://doi.org/10.1016/j.strusafe.2019.101921.

Zhang, W., Wang, W., Nicholson C., 2017. Resilience-based post-disaster recovery strategies for road-bridge networks, Structure and Infrastructure Engineering, 13(11), 14041413, doi: 10.1080/15732479.2016.1271813 